\title{
Factors Affecting Sporogenic and Myceliogenic Germination of Sclerotia of Colletotrichum coccodes
}

\author{
S. Sanogo, Former Graduate Research Assistant, and S. P. Pennypacker, Professor, Department of Plant Pathology, \\ The Pennsylvania State University, University Park 16802
}

\begin{abstract}
Sanogo, S., and Pennypacker, S. P. 1997. Factors affecting sporogenic and myceliogenic germination of sclerotia of Colletotrichum coccodes. Plant Dis. 81:333-336.

Two types of germination were exhibited by Colletotrichum coccodes when sclerotia, placed on moist filter papers in petri plates that were then either not sealed or sealed with Parafilm, were incubated for 5 days at temperatures of 10 to $34^{\circ} \mathrm{C}$ under a 14-h photoperiod. In sealed plates, germination was primarily myceliogenic; in nonsealed plates, sclerotial germination was only sporogenic. Setose, slightly orange-colored conidial masses were profusely produced on sclerotia at all temperatures greater than $10^{\circ} \mathrm{C}$. Hyaline masses of conidia with sparse setae were produced on sclerotia maintained in complete darkness, and no mycelia formed in the sealed plates. In all temperature treatments, the numbers of colony-forming units per 100 sclerotia were greater in nonsealed than in sealed plates and greater under light than in complete darkness.
\end{abstract}

Anthracnose of tomato (Lycopersicon esculentum Mill.), a major disease of ripe fruit, was reported in the United States in 1891 and now occurs in Europe, Asia, and North America (17). Although several species of Colletotrichum cause typical anthracnose symptoms on tomato fruit, $C$. coccodes (Wallr.) S. J. Hughes is the major fungal pathogen associated with tomato fruit anthracnose in North America. The fruit are commonly infected by hyphae from sclerotia and conidia produced on sclerotia or in acervuli on plant surfaces $(9,12,13)$. The fungus may survive as sclerotia in soil and as sclerotia and mycelium on tomato debris over a wide range of temperatures and soil depths $(2,3,6,7,10,11)$. The fungus may also persist from 1 to 3 years or longer on other hosts, including weeds $(11,14)$.

While much is known about the source of the fungal inoculum, there are few reports on the effects of environmental factors on inoculum production. A better understanding of the environmental conditions affecting inoculum production by C. coccodes may contribute to the development of improved management strategies for the control of tomato anthracnose. This study was conducted to assess the effects of temperature, light, and aeration on sporogenic germination of sclerotia of C. coccodes. Preliminary reports have been published $(15,16)$.

Corresponding author: S. P. Pennypacker E-mail: SPP@PSU.EDU

Accepted for publication 20 January 1997.

Publication no. D-1997-0227-04R

(C) 1997 The American Phytopathological Society

\section{MATERIALS AND METHODS}

Production and maintenance of sclerotia. Preliminary investigations of pathogenicity and virulence of $C$. coccodes on ripe tomato fruit revealed little variability among isolates from New York, Michigan, and Pennsylvania. Therefore, isolate TF1, obtained from naturally infected tomato fruit harvested from a research field plot at the Russell E. Larson Agricultural Research Center, Rock Springs, Centre County, Pennsylvania $\left(40^{\circ} 42^{\prime} 53^{\prime \prime} \mathrm{N}, 77^{\circ} 56^{\prime} 25^{\prime \prime} \mathrm{W}\right)$, was used in this study. Pathogenicity was maintained by inoculating ripe tomato fruit with this isolate every 6 to 8 weeks. Tissue from the inoculated fruit was then plated on potato-dextrose agar (PDA) (Difco Laboratories, Detroit, MI) acidified with 1 $\mathrm{ml}$ of $25 \%$ lactic acid per liter (1). Actively growing mycelium was used to establish a stock culture of the isolate.

For sclerotial production, PDA in plastic petri plates ( $9 \mathrm{~cm}$ in diameter) was seeded with 5-mm agar disks from a 7-day-old culture of $C$. coccodes. The plates were then incubated at $25^{\circ} \mathrm{C}$ in the dark for 6 weeks. Sclerotia formed on the plates were harvested according to the procedures described by Farley (7), surface sterilized as described by Wicklow and Donahue (20), air dried, and stored at $4^{\circ} \mathrm{C}$ until needed. Germinability of the air-dried sclerotia was determined by seeding each of four glass petri plates $(5 \mathrm{~cm}$ in diameter) containing water agar (Difco Laboratories, Detroit, MI) with 25 sclerotia. Plates were incubated in darkness at $28^{\circ} \mathrm{C}$ for $72 \mathrm{~h}$, and the total number of sclerotia that had germinated was recorded. The average diameter of the sclerotia used in this study was 254 $\mu \mathrm{m}$, and the average germinability of 6week-old sclerotia was $97 \%$.
Experiment A: effect of temperature and aeration on conidial production on sclerotia under light. Conidial production on sclerotia was assessed in temperaturecontrolled chambers (model RI-50-555-A, Revco, Rheem Manufacturing Co., Asheville, NC) set at 10,14, 18, 22, 26, 30, and $34^{\circ} \mathrm{C}$ with a 14 -h photoperiod. Radiation intensity of the cool-white fluorescent lamps was measured with an Eppley Precision Pyranometer (model PSP, The Eppley Laboratory, Newport, RI) sensitive from 280 to $2,800 \mathrm{~nm}$. The average irradiance was about $30 \mathrm{~W} \mathrm{~m}^{-2}$ at the surface of sclerotia. Glass petri plates $(9 \mathrm{~cm}$ in diameter), each containing at least 150 sclerotia on two layers of filter paper (Grade 415, VWR Scientific, Philadelphia, PA) moistened with $3 \mathrm{ml}$ of distilled water, were maintained at each temperature treatment for 5 days. Sclerotia were transferred with a camel's-hair brush onto the filter papers. Plates were either not sealed or sealed with Parafilm (American National Can, Greenwich, CT). Actual temperature at the surface of sclerotia was estimated by a type-T thermocouple inserted into each plate. Differences in temperature between sealed and nonsealed plates were within $\pm 1^{\circ} \mathrm{C}$. The initial water potential within each plate, determined by a soil water activity meter (AquaLab model CX-2T, Decagon Devices, Pullman, WA), was about $-150 \mathrm{~J} / \mathrm{kg}(-1.5$ bars). Water was added to the nonsealed plates every $48 \mathrm{~h}$ to maintain a constant water potential. At the end of the 5-day period, sporulation on sclerotia was assessed by observing 100 sclerotia on each plate. A sclerotium was considered to have sporulated if conidial masses were present on the sclerotium surface. The mean percentage of sporulated sclerotia was computed for each temperature level. For each plate, the 100 observed sclerotia were suspended and mixed for $30 \mathrm{~s}$ in 5 $\mathrm{ml}$ of distilled water contained in 30-ml glass test tubes. Approximately $100 \mathrm{mg}$ of sterile white sand was added to each tube to facilitate release of conidia from sclerotia during mixing. The resulting suspension was passed through three layers of cheesecloth, and a 1-ml aliquot of the filtered suspension was spread over the surface of acidified PDA in petri plates and incubated at $22^{\circ} \mathrm{C}$ for $72 \mathrm{~h}$. The numbers of colony-forming units were recorded, and the average number of colony-forming units was computed for each temperature level. 
Experiment B: effect of temperature and aeration on conidial production on sclerotia in the absence of light. Experiment $\mathrm{B}$ was identical to experiment $\mathrm{A}$, except that it was conducted in complete darkness and at treatment temperatures of $10,16,22,28$, and $34^{\circ} \mathrm{C}$.

Experimental design. Three incubators were available when experiment A was initiated. Therefore, only three of the seven temperature levels were tested at one time. The experiment was conducted as a twofactor experiment in a split plot arranged in a balanced incomplete block design. Temperature levels were assigned to the whole plots and aeration levels (sealed and nonsealed) to the subplots. Each treatment combination was replicated three times, and each replication consisted of two plates. The experiment was conducted twice. Five incubators were available for experiment $\mathrm{B}$, which was performed as a two-factor (temperature and aeration) experiment in a split plot with whole unit (temperature) arranged in a randomized complete block design. Experiment B was conducted three times.

Data analysis. For each experiment, regression models were used to describe the relationship between temperature and sporulation. Logarithmic and arcsine square root transformations were applied to data pertaining to numbers of colony-forming units and proportions, respectively. In experiment $\mathrm{A}$, each temperature level did not occur in every block, which may have caused the responses for temperature levels to contain the effects of some, but not all, of the blocks. To remove differences caused by block effects from comparison of temperature levels, adjusted means for the response variables were computed with a FORTRAN computer program (4). Preliminary analyses indicated no significant difference among the replicates of each experiment. Therefore, the data for both sealed and nonsealed plates were pooled and subjected to the following regression model (19):

$$
Y=b_{0}+b_{1} * A+b_{2} * T+b_{3} * T^{2}
$$

in which $Y$ is the arcsine square roottransformed proportion of sporulated sclerotia (or Naparian logarithm-transformed colony-forming units); $A$ is the indicator variable for aeration $(A=0$ for sealed, and

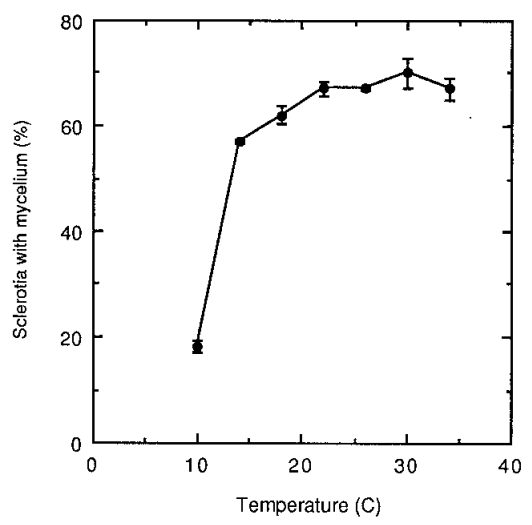

Fig. 2. Effect of temperature on myceliogenic germination of sclerotia of Colletotrichum coccodes in sealed petri plates after a 5-day exposure to a 14-h photoperiod. Each data point is the mean of six values. Vertical bars represent standard deviations.
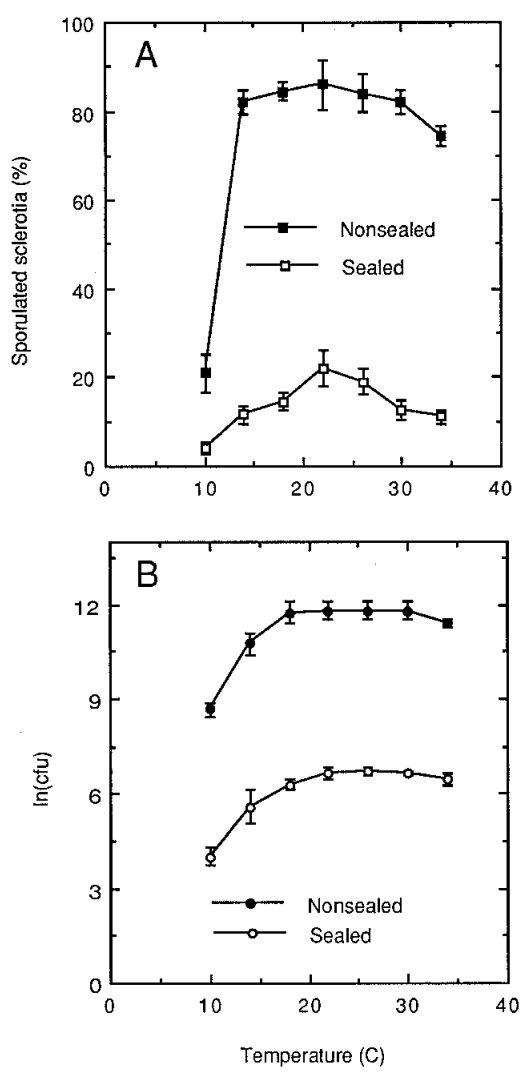

Fig. 3. Effects of temperature and aeration on sporogenic germination of sclerotia of Colletotrichum coccodes after a 5-day exposure to a 14-h photoperiod. (A) Percentage of sclerotia that sporulated, and (B) number of colony-forming units per 100 sclerotia (log-transformed). Each data point is the mean of six values. Vertical bars represent standard deviations.
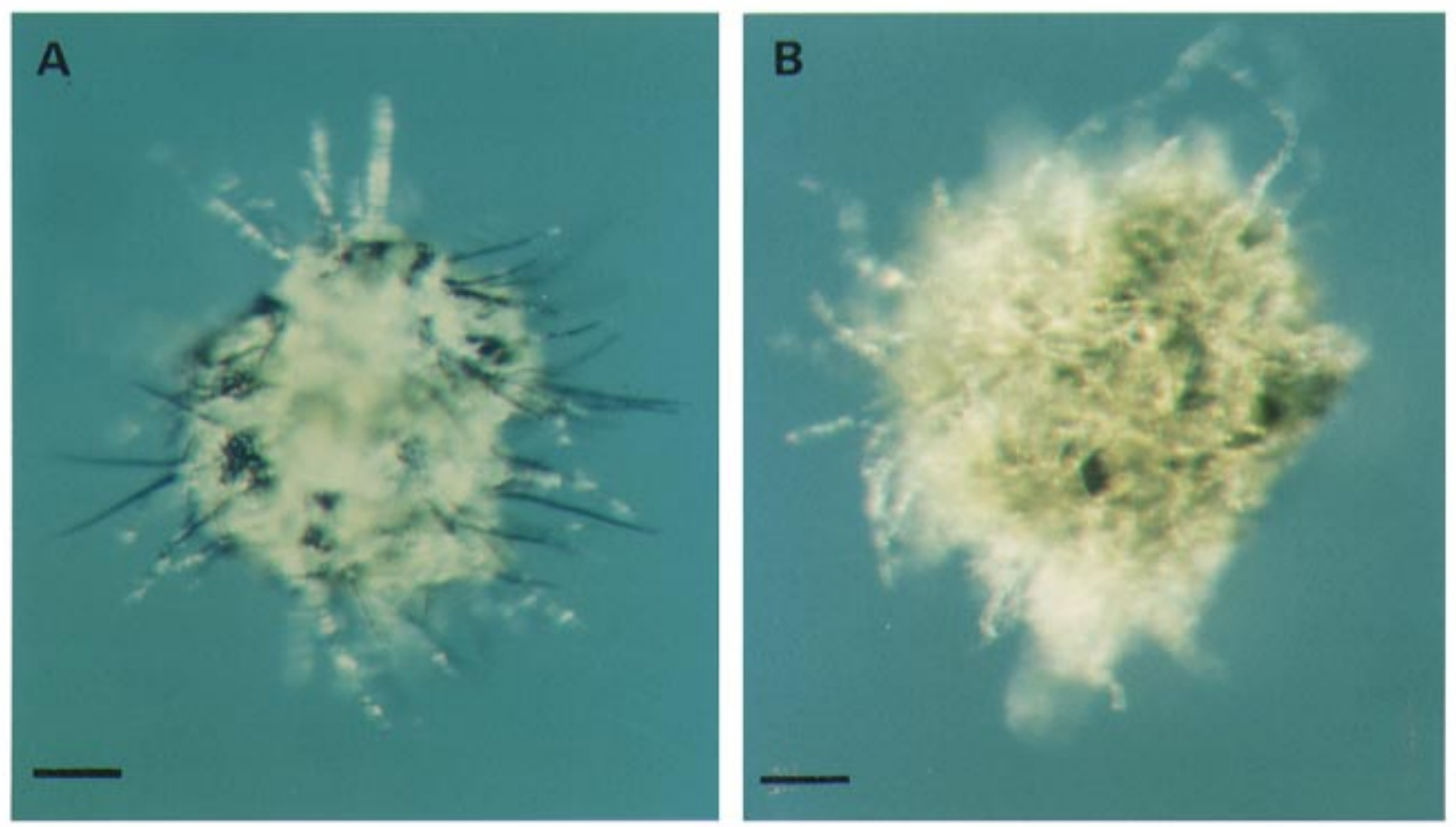

Fig. 1. Sclerotia of Colletotrichum coccodes enclosed in nonsealed (aerated) petri plates (A) produced setae and conidial masses and those in sealed plates (B) produced abundant mycelial growth after a 5-day exposure to a 14-h photoperiod. Bar $=35 \mu \mathrm{m}$. 
$A=1$ for nonsealed); and $T$ and $T^{2}$ are linear and quadratic terms, respectively, for temperature $\left({ }^{\circ} \mathrm{C}\right)$. In this model, sporulation was viewed to be dependent upon aeration and temperature (linear and quadratic). Adequacy of the regression models was determined on the basis of the goodness-of-fit between expected and observed values, randomness and normality of residuals, and value of the coefficient of determination.

\section{RESULTS}

In experiment $\mathrm{A}$, conidia were produced on sclerotia within the range of temperatures tested. Sclerotia profusely formed setae and light orange-colored conidial masses in nonsealed plates at all temperatures greater than $10^{\circ} \mathrm{C}$ (Fig. 1A). In contrast, sclerotia in sealed plates produced mostly mycelium (Figs. 1B and 2). No discernible mycelium formed on sclerotia in nonsealed plates. Under the conditions established within nonsealed petri plates, sporulation of sclerotia was approximately four times the sporulation in sealed plates at temperatures from 14 to $34^{\circ} \mathrm{C}$ (Fig. 3A). The relationship between the percentage of sclerotia that sporulated and temperature also displayed slightly different curve trends for sealed and nonsealed plates. In the sealed plates, the percentage of sclerotia that sporulated increased with increasing temperature up to $22^{\circ} \mathrm{C}$ and then slightly decreased through $34^{\circ} \mathrm{C}$. Conversely, in the nonsealed plates, the percentage of sclerotia that sporulated was low at $10^{\circ} \mathrm{C}$ and increased approximately threefold at $14^{\circ} \mathrm{C}$ and then remained nearly constant through $30^{\circ} \mathrm{C}$ before slightly decreasing at $34^{\circ} \mathrm{C}$. The parameters of the best-fitting models for each group are shown in Table 1. Visual examinations indicated that residuals from the fitted equation were normal with no discernible patterns.

The log-transformed numbers of colonyforming units per 100 sclerotia in both sealed and nonsealed plates displayed similar trends (Fig. 3B). The numbers of colony-forming units increased with temperature up to $18^{\circ} \mathrm{C}$, remained nearly constant through $30^{\circ} \mathrm{C}$, and slightly decreased at $34^{\circ} \mathrm{C}$. The parameters of the best-fitting models for each group, estimated from the pooled transformed data, are shown in Table 1 along with associated statistics.

Conidial production on sclerotia subjected to the temperature treatments in darkness (experiment B) was greater in nonsealed than in sealed plates. In both sealed and nonsealed plates, sclerotia sparsely produced setae and hyaline masses of conidia (Fig. 4). Sclerotia in sealed plates maintained in the dark formed virtually no mycelium. The graphical representations of sporulation over temperature showed similar trends for sclerotia in either sealed or nonsealed plates (Fig. 5A). The percentages of sclerotia that sporulated increased with temperature up to $22^{\circ} \mathrm{C}$ and then decreased through $34^{\circ} \mathrm{C}$. The logarithm-transformed numbers of colony-forming units (Fig. 5B) increased initially with temperature up to $16^{\circ} \mathrm{C}$ in the nonsealed plates, remained constant through $28^{\circ} \mathrm{C}$, and then declined at $34^{\circ} \mathrm{C}$. In the sealed plates, the numbers of colony-forming units peaked at $28^{\circ} \mathrm{C}$ before decreasing sharply. Parameters of the models that best describe the pooled transformed data are displayed in Table 2.

\section{DISCUSSION}

Temperature, aeration, and light exerted a significant effect on sclerotial germination of $C$. coccodes. The range of temperatures selected for the study represents those usually encountered in the field during the summer tomato-growing season in Pennsylvania. Results of this investigation indicate that myceliogenic and sporogenic germination of sclerotia occurs over a wide range of temperatures, as has been shown for conidial germination and fruit infection $(5,9)$.

Table 1. Equation parameters and associated statistics for effects of aeration and temperature on sporogenic germination of sclerotia of Colletotrichum coccodes in the presence of light ${ }^{\mathrm{w}}$

\begin{tabular}{lccccccc}
\hline & \multicolumn{9}{c}{ Parameter estimates $^{\mathbf{x}}$} & & & \\
\cline { 2 - 5 } Variable & $\boldsymbol{b}_{\mathbf{0}}$ & $\boldsymbol{b}_{\mathbf{1}}$ & $\boldsymbol{b}_{\mathbf{2}}$ & $\boldsymbol{b}_{\mathbf{3}}$ & $\boldsymbol{P}(>\boldsymbol{F})$ & $\boldsymbol{R}^{\mathbf{2}}$ & $\boldsymbol{R}^{\mathbf{2}}$ \\
\hline Arcsine $\sqrt{ } p^{\mathrm{y}}$ & -44.60 & 38.70 & 6.13 & -0.126 & 0.000 & 0.93 & 0.92 \\
& $(9.972)$ & $(2.437)$ & $(0.979)$ & $(0.022)$ & & & \\
$\ln (\mathrm{CFU})^{\mathrm{z}}$ & -0.632 & 5.020 & 0.583 & -0.011 & 0.000 & 0.99 & 0.98 \\
& $(0.459)$ & $(0.112)$ & $(0.045)$ & $(0.001)$ & & & \\
\hline
\end{tabular}

${ }^{\mathrm{w}}$ Models were derived from 28 observations pooled across two experimental replications, two aeration levels, and seven temperatures.

${ }^{x}$ Estimated parameters $b_{0}, b_{1}, b_{2}$, and $b_{3}$ and standard deviations (in parentheses) for the regression model $Y=b_{0}+b_{1} * A+b_{2} * T+b_{3} * T^{2}$, in which $Y=$ the arcsine square root-transformed proportion of sporulated sclerotia and Naparian logarithm-transformed colony-forming units; $A=$ indicator variable for aeration ( $A=0$ for sealed, and $A=1$ for nonsealed); and $T$ and $T^{2}$ are linear and quadratic terms, respectively, for temperature $\left({ }^{\circ} \mathrm{C}\right)$.

${ }^{\mathrm{y}} p=$ proportion of sporulated sclerotia.

${ }^{\mathrm{z}} \mathrm{CFU}=$ colony-forming units per 100 sclerotia.
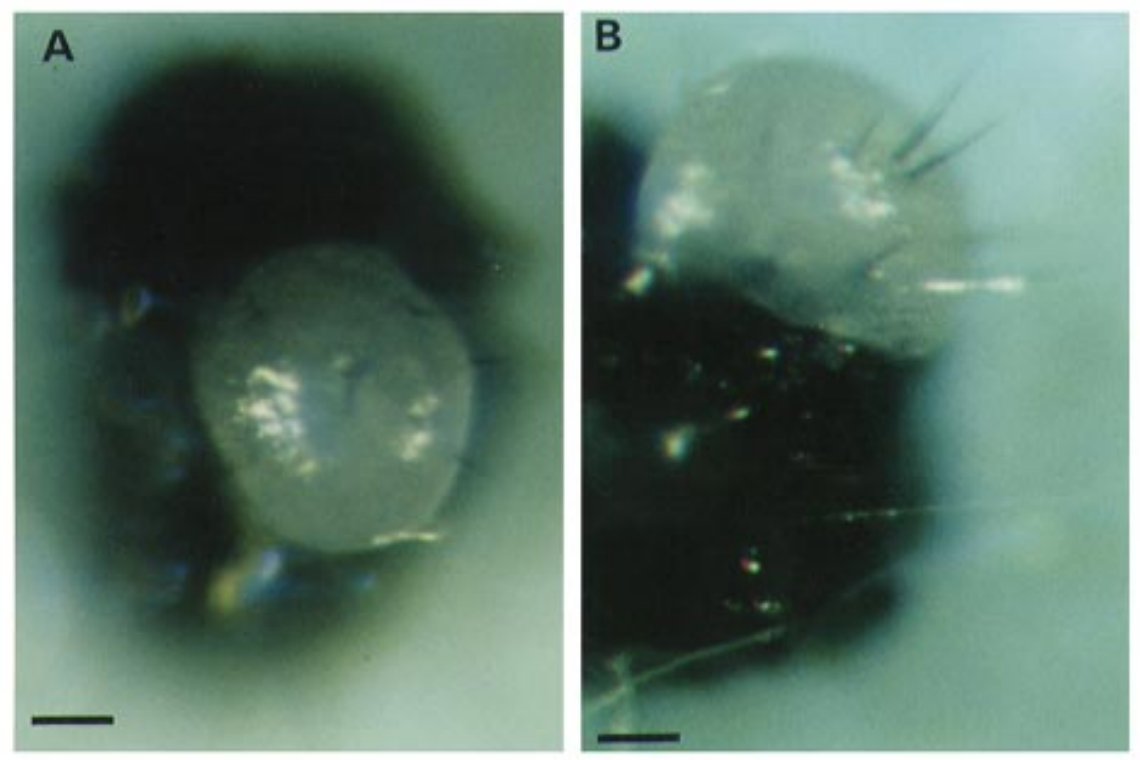

Fig. 4. Germination of sclerotia of Colletotrichum coccodes after 5 days of darkness. (A) Top view and (B) side view of globose and whitish conidial mass with setae produced on sclerotia. $\mathrm{Bar}=63 \mu \mathrm{m}$. 

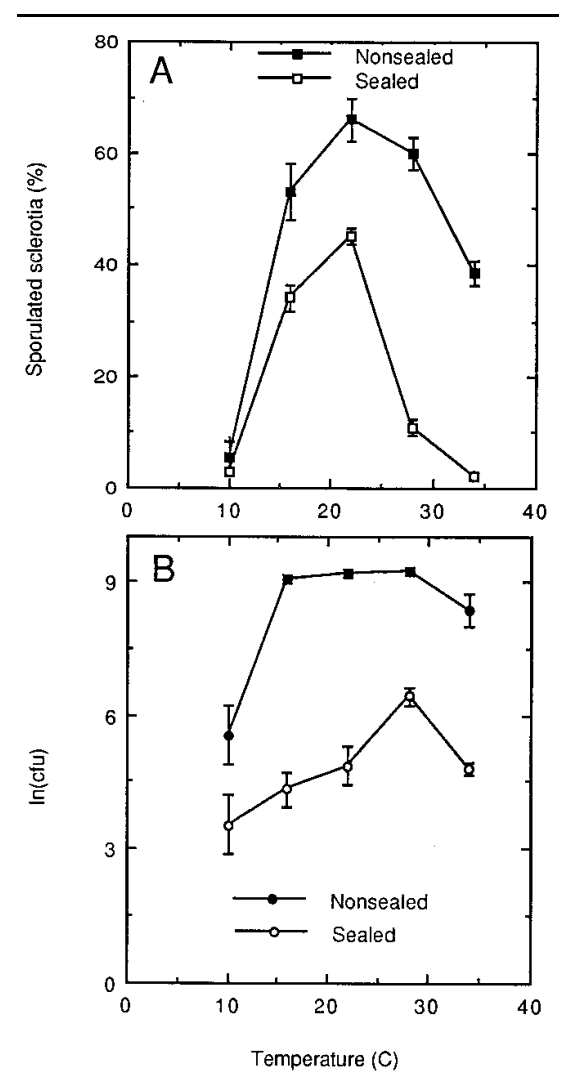

Fig. 5. Effects of temperature and aeration on sporogenic germination of sclerotia of Colletotrichum coccodes after 5 days of darkness. (A) Percentage of sclerotia that sporulated, and (B) number of colony-forming units per 100 sclerotia (log-transformed). Each data point is the mean of three values. Vertical bars represent standard deviations.

ago. Tabak and Cooke (18) thoroughly reviewed the early work on this subject. Apparently, suppression of sporulation and other microbial activities in closed environments may be ascribed to an oxygen deficit or to an accumulation of $\mathrm{CO}_{2}$ (18). Neither of these two phenomena can be concluded in the present study because the gaseous environment in the sealed plates was not analyzed.

Of the four experimental treatments derived from the combination of aeration levels (sealed and nonsealed plates) and light regime (light and darkness), conditions established in the sealed plates subjected to light are not encountered in the field. Therefore, the abundant mycelium formation observed under these conditions is of no significance in the field. Sclerotia in the nonsealed plates subjected to light and darkness could be comparable to sclerotia on field soil surfaces exposed to sunlight and under dense plant canopies, whereas sclerotia in the sealed plates maintained in darkness could approximate sclerotia buried at some soil depth where little or no air exchange occurs. This study suggests that conidia may be produced more abundantly on sclerotia on the soil

Table 2. Equation parameters and associated statistics for effects of aeration and temperature on sporogenic germination of sclerotia of Colletotrichum coccodes in darkness ${ }^{\mathrm{w}}$

\begin{tabular}{lccccccc}
\hline & \multicolumn{9}{c}{ Parameter estimates $^{\mathbf{x}}$} & & & \\
\cline { 2 - 5 } Variable & $\boldsymbol{b}_{\mathbf{0}}$ & $\boldsymbol{b}_{\mathbf{1}}$ & $\boldsymbol{b}_{\mathbf{2}}$ & $\boldsymbol{b}_{\mathbf{3}}$ & $\boldsymbol{P}(>\boldsymbol{F})$ & $\boldsymbol{R}^{\mathbf{2}}$ & $\boldsymbol{R a}^{\mathbf{2}}$ \\
\hline Arcsine $\sqrt{ } p^{\mathrm{y}}$ & -68.0 & 17.8 & 9.31 & -0.205 & 0.000 & 0.84 & 0.82 \\
& $(9.906)$ & $(2.660)$ & $(0.983)$ & $(0.022)$ & & & \\
$\ln (\mathrm{CFU})^{\mathrm{z}}$ & -2.27 & 3.47 & 0.637 & -0.0125 & 0.000 & 0.91 & 0.90 \\
& $(0.926)$ & $(0.248)$ & $(0.091)$ & $(0.002)$ & & & \\
\hline
\end{tabular}

${ }^{\mathrm{w}}$ Models were derived from 30 observations pooled across three experimental replications, two aeration levels, and five temperatures.

${ }^{\mathrm{x}}$ Estimated parameters $b_{0}, b_{1}, b_{2}$, and $b_{3}$ and standard deviations (in parentheses) for the regression model $Y=b_{0}+b_{1} * A+b_{2} * T+b_{3} * T^{2}$, in which $Y=$ the arcsine square root-transformed proportion of sporulated sclerotia and Naparian logarithm-transformed colony-forming units; $A$ = indicator variable for aeration ( $A=0$ for sealed, and $A=1$ for nonsealed); and $T$ and $T^{2}$ are linear and quadratic terms, respectively, for temperature $\left({ }^{\circ} \mathrm{C}\right)$.

${ }^{\text {y }} p=$ proportion of sporulated sclerotia.

${ }^{\mathrm{z}} \mathrm{CFU}=$ colony-forming units per 100 sclerotia.

surface than on sclerotia buried in soil. Results further indicate that the magnitude of conidial production on sclerotia on soil surfaces exposed to sunlight may be greater than that on sclerotia under dense plant canopies.

The epidemiological significance of sporogenic germination in the field depends on the location of sclerotia. Sclerotia on a soil surface exposed to sunlight would be expected to play a significant role in the dispersal of $C$. coccodes because they represent a source of conidial inoculum readily available for dissemination by rain splash. However, sclerotia on a soil surface under dense plant canopies or within the soil would produce conidia that may infect plant parts in contact with the soil.

Inoculum of an adequate quantity and quality is required for a disease to occur. Kendrick and Walker (12) showed that sclerotia in the soil or in association with plant debris are the source of primary inoculum of $C$. coccodes in epidemics of tomato anthracnose. However, no mention was made of the effect of the physical environment on production of conidia from sclerotia. This study is the first known report of how temperature, aeration, and light influence the occurrence and magnitude of myceliogenic and sporogenic germination of sclerotia of $C$. coccodes.

\section{ACKNOWLEDGMENTS}

Financial support for this research was provided by the Pennsylvania Agricultural Experiment Station. We thank Richard E. Stevenson for technical assistance. This is a portion of $\mathrm{S}$. Sanogo's Ph.D. dissertation submitted to The Pennsylvania State University. Contribution 2033, Department of Plant Pathology, The Pennsylvania Agricultural Experiment Station.

\section{LITERATURE CITED}

1. Adams, P. B. 1975. Factors affecting survival of Sclerotinia sclerotiorum in soil. Plant Dis. Rep. 59:599-603.

2. Blakeman, J. P., and Hornby, D. 1966. The persistence of Colletotrichum coccodes and Mycosphaerella ligulicola in soil, with special reference to sclerotia and conidia. Trans. Br. Mycol. Soc. 49:227-240

3. Chesters, C. G., and Hornby, D. 1965. Studies on Colletotrichum coccodes. II. Alternative host tests and tomato fruit inoculation using a typical tomato root isolate. Trans. Br. Mycol. Soc. 48:583-594.

4. Davies, R. G. 1971. Computer Programming in Quantitative Biology. Academic Press, London.

5. Dillard, H. R. 1988. Influence of temperature, $\mathrm{pH}$, osmotic potential, and fungicide sensitivity on germination of conidia and growth from sclerotia of Colletotrichum coccodes in vitro. Phytopathology 78:1357-1361.

6. Dillard, H. R. 1990. Survival of Colletotrichum coccodes in New York. (Abstr.) Phytopathology 80:1026.

7. Farley, J. D. 1976. Survival of Colletotrichum coccodes in soil. Phytopathology 66:640-641.

8. Frost, R. R. 1964. Seta formation in Colletotrichum spp. Nature (London) 201:730-731.

9. Fulton, J. P. 1948. Infection of tomato fruits by Colletotrichum phomoides. Phytopathology 38:235-246.

10. Hornby, D. 1968. Studies on Colletotrichum coccodes. III. Some properties of the fungus in soil and tomato roots. Trans. Br. Mycol. Soc. 51:541-553.

11. Illman, W. I., Ludwig, R. A., and Farmer, J. 1959. Anthracnose of canning tomatoes in Ontario. Can. J. Bot. 37:1237-1246.

12. Kendrick, J. B., Jr., and Walker, J. C. 1948. Anthracnose of tomato. Phytopathology 38 247-260.

13. Pantidou, M. E., and Schroeder, W. T. 1956. Foliage as a source of secondary inoculum for tomato anthracnose. Phytopathology 45:338345.

14. Raid, R. N., and Pennypacker, S. P. 1987. Weeds as hosts for Colletotrichum coccodes. Plant Dis. 71:643-646.

15. Sanogo, S., Pennypacker, S. P., and Stevenson, R. 1994. Effect of temperature on conidial production on sclerotia of Colletotrichum coccodes. (Abstr.) Phytopathology 84:1079.

16. Sanogo, S., Pennypacker, S. P., and Stevenson, R. 1994. Relation of temperature, aeration, and moisture on sporogenic germination of sclerotia of Colletotrichum coccodes. (Abstr.) Phytopathology 84:1375.

17. Sherf, A. F., and MacNab, A. A. 1986 Vegetable Diseases and Their Control. 2nd ed. Wiley-Interscience, New York. pp. 629-634.

18. Tabak, H. H., and Cooke, W. B. 1968. The effects of gaseous environments on growth and metabolism of fungi. Bot. Rev. 34:126252.

19. Weisberg, S. 1980. Applied Linear Regression. John Wiley \& Sons, New York.

20. Wicklow, D. T., and Donahue, J. E. 1984 Sporogenic germination of sclerotia of Aspergillus flavus and A. parasiticus. Trans. $\mathrm{Br}$. Mycol. Soc. 82:621-624. 